\title{
THEORETICAL BASIS AND MODELS FOR DEVELOPING STUDENTS' VALUES IN PRIMARY EDUCATION
}

MSc Violeta Panev - OOU Vlado Tasevski, Skopje, Macedonia

E-mail: violetapanev@yahoo.com

A R T I C L E I N F O

Review Article

Received: January, 09.2020.

Revised: February, 10.2020.

Accepted: February, 24.2020.

doi: 10.5937/IJCRSEE2001081P

UDK

37.015.31-057.87

Keywords:

value based education,

values,

values orientations,

primary school

theoretical models.

\section{A B S T R A C T}

Values are the core in the educational process both from a theoretical point of view and from the aspect of the teaching practice. The school assumes the main function in values' acquisition in pupils and as a public institution it produces the values of the wider social community and society. In acquiring the values in the school, not only parents and teachers' influence takes place, but the background is a colourful diversity of political, social, economic, religious and cultural values of various groups and interests. The priority of selected values in a school curriculum represents a palette of life activities in the school and also the life events beyond the social community. They should be carefully chosen, realized and valued. Their realization does not ooften take place in an easy way because the values are not explicitly represented in the curriculum and are not equally understood by all subjects in the teaching practice. The acquisition of primary values in young people increases the possibility for favourable development of other values and forming a complete personality. Therefore, this paper will try to present several theoretical models of educational practice that support opportunities for teaching character and students' values acquisition in a modern school environment. The models themselves contribute to the development and acquisition of given values in the pupils. Some of them are complement and create possibility to solve some current issues from everyday school life and enable an easier transition from traditional to modern teaching practice.

\section{INTRODUCTION}

Values are defined as a concept that hold within something good (beauty, love, honesty, etc.) and as a personal and social choice rather than a preference. They are related to the beliefs, attitudes, and feelings that an individual desires. Values are also defined as objects, activities; experiences that promote wellbeing, a term elaborated further in this paper that is a result of an existence and practice of values. In the philosophical debates in the lists of Schwartz (10 value types) and Rockych list of 36 fundamental values (Rokeach, 1973), values are described and named as principles and fundamental beliefs and standards which serve as guidelines for

Corresponding Author

MSc Violeta Panev - OOU Vlado Tasevski, Skopje, Macedonia

E-mail: violetapanev@yahoo.com our behaviour or preferences, decisions and beliefs.

Closely related to the theme of values are the relatively enduring goals of value based education that an individual or a group of people want to develop and acquire in the pupils."These goals constitute the value system that corresponds to the hierarchy of universal values from which general values are derived, but an individual also learns according to the values he chooses himself, according to his abilities and life opportunities." (Mijatovic et all, 1999, p.655).

Educational goals, whether valuebased or cognitive are inseparable, and their study and understanding helps pupils develop and nurture values in order to be their true determinant of a life filled with honesty, integrity, justice, care, and respect for others and help to make them responsible citizens who appreciate beauty and nature.

This work is licensed under a Creative Commons Attribution - NonCommercial - NoDerivs 4.0. The article is published with Open Access at www.ijcrsee.com 


\section{THEORETICAL MODELS AS A TOOL FOR VALUE-BASED EDUCATION, FORMING AND DEVELOPING VALUES}

Values are central to the educational process, both theoretically and in terms of teaching practice. The school, with its teaching staff and family members, assumes the main function of their adoption, but as a public institution it also undertakes and produces the values of the wider community and the whole society.

The school today is often a place of struggle for different values priorities and opportunities for dominant influence of different subjects and groups. However, what priorities will be of utmost importance to the school community is identified in the process of the school itself: organization, actions, curriculum, planning, work environment, discipline and communication between teachers, and school staff. Their implementation is not often easy to do because values are not explicitly represented in the curriculum and are not equally understood by all subjects in the teaching practice.

In this paper we will present theoretical models of educational practice that offer opportunities for successful realization and adoption of values in pupils in a modern school environment. Some of them are intertwined and represent an opportunity to overcome some current problems in everyday school life and help to establish an easier transition from traditional to modern teaching practice. We made a theoretical research on the theory of the positive psychology of Dr. Martin Seligman and the VIA list of 24 character values socalled personality strengths; then Carol Dweck's theory of fixed mindset and growth mindset especially useful in the enhancing the value orientations in young people; and the learning theory of "flow" developed by Mihály Csíkszentmihályi with the teacher-set activities that arouse excitement, interest and achievement in learning and others.

Acquiring individual values in young people in these models increased the potential for favourable development and learning of other values in pupils and took the opportunity of forming complete and quality young persons. One of the reasons for pupils' misbehaviour and communication difficulties both in and outside the school learning environment still is the lack of sufficiently acquired and thoroughly adopted values.
According to this we can state that pupils' acquisition of values and development of value orientations closely corresponds to the favourable school climate, discipline and the degree of values development of the school curriculum. For example, if pupils develop the value of diligence and work habits, they would be able to develop the value of perseverance and grit and achieve better learning outcomes, or if the value of peace climate develops, the pupils would be able to develop empathy and to cooperate more successfully with each other and minimize the disciplinary problems of violence and conflicts that take away time during the lesson. In line with this starting point, we have explored three theoretical models that help foster and shape young people's values. They cover all phases of this process, from their cognitive and emotional level of acquisition to their realization or action. Acting in harmony with these beliefs certainly requires a reinforcement of one's positive qualities, will, and a personality.

\subsection{Dr. Martin Selingman`s positive psychology and the science of character ( 24 character strengths)}

The Positive Psychology is a branch of psychology that studies human strengths, virtues and the factors that contribute to a fulfilling and meaningful life. It has three central pillars: positive experiences, positive individual traits and positive institutions. The founder and leader of Positive Psychology is Dr. Martin Seligman, who is known for research such as perseverance, learned helplessness, depression, optimism and pessimism and is a recognized authority in the field of wellbeing. The theme of the positive psychology, according to him, is well-being, the golden standard for measuring and evaluating it is the blooming personality, while the goal of positive psychology is flourishing.

In his latest book, "Flourish," which deals precisely with the blossoming of the human personality, Seligman explains "The Theory of Well-being" and the way it can be measured. He thinks that five elements of "wellbeing" which are contained in the acronym PERMA are necessary. They are: P- Positive emotion, E-Engagement, R- Relationships, M- Meaning and A- Achievement. According to him, "Positive emotion" means a positive feeling that can only be assessed subjectively; "Engagement" means involvement in a state of flow which is a pleasant activity for the 
person performing it; "Relationships" are relations with friends, family, intimate and/or social relationships; "Meaning" is a sense of fulfilment and significance to serve and belong to something greater than oneself and "I"; and "Accomplishment" is an achievement, success that is attained even when it does not bring positive emotions, or is not associated with positive relationships. Seligman (2011) believes that these five elements can help people achieve a life of fulfilment, happiness and meaning. This model can also be applied to institutions to develop programs to help people acquire new cognitive and emotional tools. (see Figure 1)



Figure 1. The five pillars of the PERMA Model (Martin Seligman, 2018)

As part of well-being, happiness itself does not make sense for life, that is, it is not enough. Seligman points to what enables nurturing talents and building deep, lasting relationships with others; the way to enjoy pleasure, and how to make a significant contribution to the world, in a word, he shows what enables an individual to flourish. Wellbeing occupies the central and primary front part in the model, and Happiness (or positive emotion) becomes one of the five pillars of positive psychology, i.e. the theory of well-being called PERMA as the constant building blocks for a life of deep fulfilment. Neither of them defines well-being, but each of them leads to it. Thus he distinguishes the theory of happiness (Seligman, 2011) which is reflected only in life satisfaction and the theory of well-being, which besides happiness rests on the five aforementioned pillars.

Seligman guides us how to apply the PERMA model to people's lives through the five pillars: a positive perspective, engagement in the activities that make people happy, focusing on quality relationships with other people and family, leading meaningful lives and striving for new achievements. His twodecade work on building optimism, motivation and character shows how to get the most out of a life, discovering a new wellbeing theory of what makes life good for individuals and for communities and nations as well as; the way innovative schools can educate about fulfilling life, and not just how to succeed at work; and how corporations can simultaneously improve performance and increase employees' wellbeing.
In addition to Schwartz and Rockych lists (Schwartz, 1994, 2012) which are used for a long time in value research in different social groups and national areas, Seligman gives us a list of 24 character strengths he uses in his research theory of well-being as the basis of the five pillars. The deployment of the highest character forces leads to more positive emotions, meaningful life, more accomplishment and better relationships. They are the following, listed in the order of the VIA List: Creativity, Curiosity, Judgment, Love of learning, Perspective, Bravery, Perseverance, Honesty, Zest, Love, Kindness, Social intelligence, Teamwork, Fairness, Leadership, Forgiveness, Humility and modesty, Prudence, Self-regulation, Appreciation of beauty and excellence, Gratitude, Hope, Humour and Spirituality. 


\section{VIA Character Strengths \& Virtues \\ (Peterson and Seligman, 2004)}

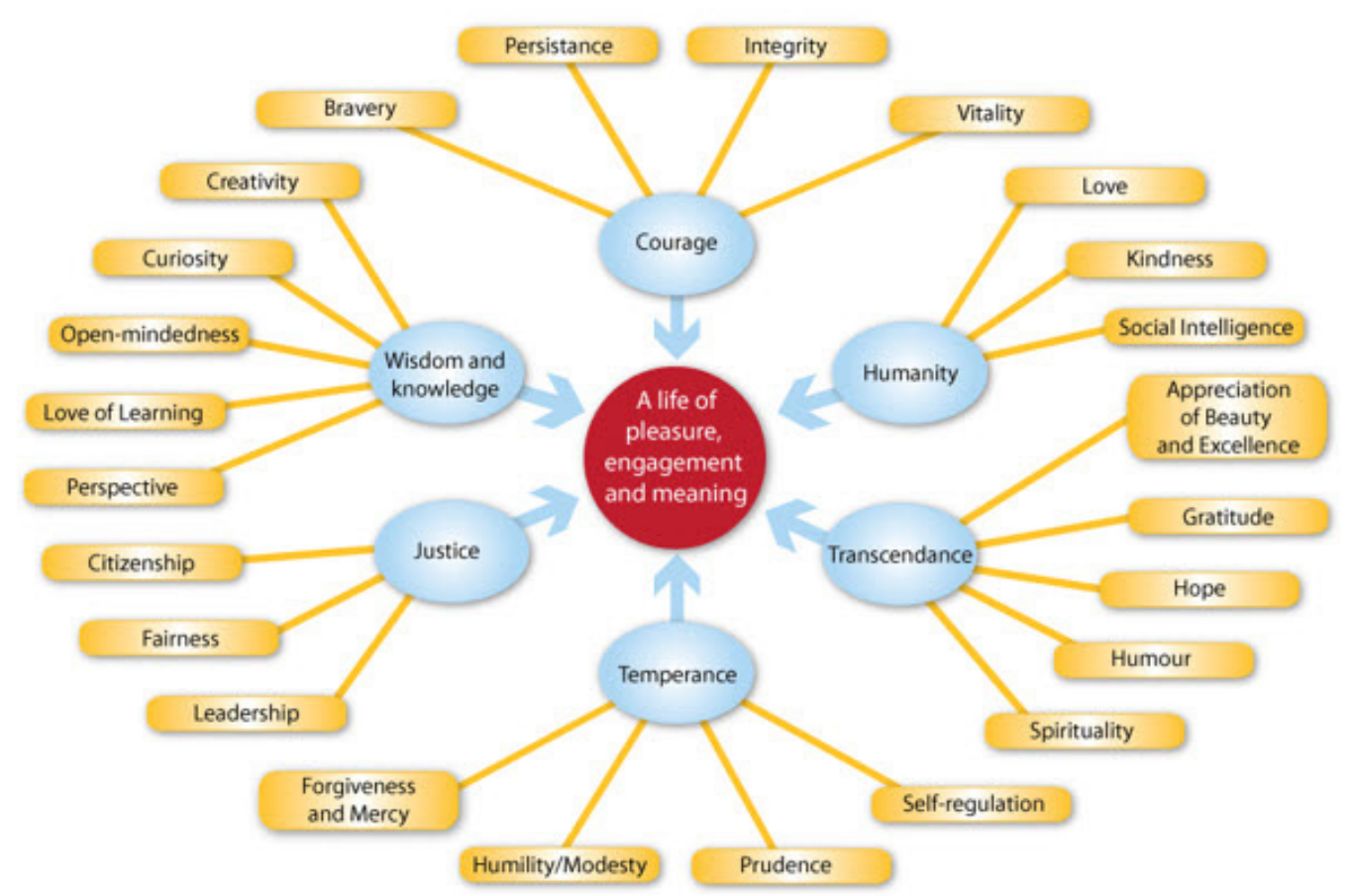

Figure 2. VIA list of 24 Character Forces and 6 virtuous categories

Values in action character strengths (Peterson and Seligman, 2004)

These values are classified or re-grouped into six character bases, i.e. Virtues categories of life flourishing, each category as a subgroup area encompassing more character strengths. (see Figure 2) They are: wisdom, courage, humanity, justice, restraint and transcendence. This classification is the skeleton of the science of positive psychology so called Character Strengths and Virtues (Peterson and Seligman, 2004). The subgroups are:

- Wisdom and knowledge: Creativity, Curiosity, Open-mindedness, Love of Learning, Perspective;

- Courage: Bravery, Perseverance, Integrity, Vitality;

- Humanity: Love, Kindness and Social Intelligence;

- Justice: Citizenship, Fairness and Leadership;

- Temperance: Forgiveness and Mercy, Humility/Modesty, Prudence and SelfRegulation;

- Transcendence: Appreciation of Beauty and Excellence, Gratitude, Hope, Humor and Spirituality.

Dr Martin Seligman says: "Character Strengths are the spine of PERMA. When you recognize and act on your character strengths, it gives you more positive emotions, more engagement, better relationships and more meaning, and thus greater accomplishment. Character strengths (listed above) are physical health, the more you have, the more you are PERMA" (Seligman, 2019). Regarding how schools should use this model and use it in the educational process, he argues that the goals of the school are two, one is to produce learning that is a traditional goal, and the other is to build well-being, which means to increase PERMA realization to a higher level. Learning is, in a way, covered by A in PERMA, where A stands for accomplishment, realization. But more important is the P-positive emotion and E-engagement. The better the pupil's relationship with the teacher, the more M-meaning reinforces A-learning achievement. If PERMA is increased, the realization of children's learning in the school will increase too. If their learning increases, so does PERMA.

With regard to the empirical validation of his theory, he recommends that if PERMA is the goal set in the classroom, it should be measured. Ways of measuring are an option and different creative opportunities for teachers, which are a process that needs to be repeated and determined if a way is found how to increase PERMA at the appropriate location, or school.

Dave Levin, (2019) winner of many 
awards in value education and leader of the most successful and renown public school in the United States (KIPP \& Relay GSE) shows us how useful it is when teachers apply these guidelines and maximize their pupils' participation and learning achievement. Through classes, discussions, interviews, and collaborations with pupils, teachers, and great educators of this century, he provides us with the opportunity and image of integrating character-based objectives throughout the lessons in learning different subject areas. Practical lessons show the primary values of his school institution and their daily realization in all subjects. Their elaboration here would be quite time consuming and we will not describe them in detail, but we will focus on the part of the evaluation of values development and the CGC (Character Growth Card) instrument used in his institution. Through it we will build on the second theoretical model of Dr. Carol Dweck's Fixed and Growth Mindset.

\subsubsection{CGC instrument, evaluation and process description}

Riverdale RCS High School (5-8 grade) uses CGC to provide feedback on their pupils' character strengths through in-depth comments in the CGC report which reinforces the message that success is a combination of habits and character strengths. Their practice has led to the following conclusions:

1. Teachers need to understand character strengths thoroughly and pay attention to the discussion of how important they are to the learning. They should also make a selfassessment using the same indicators on the card, enabling them to more fully and personally grasp these concepts, as well as develop empathy and a greater understanding of the challenges their pupils may face in increasing their own personal strengths.

2. Value-based \& Character education requires a differentiated approach depending on the age of the students. Homeroom teachers meet twice a month $(6-8$ grades $)$ to discuss the CGC and similar issues. Homeroom teachers of the same grade level come to these meetings once a month to share ideas on the best way to continue working with their grade level students. As sixth graders may have a little understanding of what these character strengths mean or what they look like, more effort and time is devoted to explicitly defining character strengths so that they thoroughly understand this area confidently. On the other hand, since the 8th grade have already got some experience with SGS for at least two years, discussions at the school are guided on a higher level by a quick overview of character strengths at the beginning of the school year and based on this a more subtle and implicit discussion of the strengths.

3. Parental involvement is crucial. Involving parents in every step of the process is important to their success. Ideally, communication about CGC related work should start from the school or management coordinator. The register of value vocabulary and language related to CGC in commentary writing makes parents excited and grateful to hear about the school activities done with their sons and daughters with the staff.

Teachers at Riverdale RCS High School use CGC (Character Growth Card) to provide feedback to students on their character strengths and character development through expanded detailed comments and reports written in each grade at the end of the first and third trimester. Once students receive report cards, they are included in a series of reflections. They need to emphasize their strengths and the areas that need improvement noted by a teacher, and select an area to set a goal to be achieved by the following trimester. As examples, Dave Levin sets out several pupils'statements out of which we selected this one:

"I aim to ask more questions this quarter. While I recognize this is hard for me, I know asking questions, both in class, and after, will help me to understand things that have been confusing me all quarter."

Once the student's goals are set, the students send the plan of goals to the teacher who made the suggested area to be improved and to their homeroom teacher. In this way, students' goals can be further enhanced by sharing them and responsibility to others.

This CGC embodies all of the character development models in this paper as a tool or an instrument for enhancing students' values that each school should select and determine as important in a given period.

\subsection{Fixed and Growth Mindset - Dr. Carol Dweck}

In order to explain Dr. Carol Dweck's theory, we first need to explain the meaning of the word "mindset". If we look for its meaning in the top foreign dictionaries, we will see that it involves a kind of way of thinking, that is, a determined mental beliefs about the 
states, things and situations. The MerriamWebster dictionary (2018) describes it as a "mental attitude or inclination", while a "fixed mindset" as a mental setting that does not allow for new situations. The Oxford Dictionary (2019) defines it as "a set of attitudes held by someone", that is, an established set of attitudes by someone.

Carol Dweck from Standford University, talks about mental attitudes and skills that enhance and optimize long-term learning. In doing so, she addresses the non-cognitive factors that drive successful learning enabled as "academic tenacity" which at the basic level means grit or diligence or disciplined commitment over a long period of time. It is a mental attitude and skill that enables the student to commit to long-term goals and endurance in challenges and learning. She believes that short-term goals cause children feel insufficiently capable and smart and even make them wish to leave school, reducing their desire and interest in learning. Some students bring these thoughts and mental attitude and skills together with them to school, but they can also be learned and developed too. Her research shows that non-cognitive factors are critical to current academic success. The research is done with African-American and Latino groups of urban children from lowincome families ( $7^{\text {th }}$ grade). Non cognitive factors include students' beliefs about themselves, their goals in school, their feelings of social belonging, and their self-regulatory skills. Measuring students' skills and mindset can predict their future performance, thus advocating for interventions that improve students' performance by changing specific ways of thinking and skills, i.e. shifting the "Fixed Mindset" to so called "Growth Mindset". On the question of how it is reflected and recognized in children Carol gives us a description in her book (Dweck 2014 et all, 4). The academically tenacious children exhibit the following characteristics and behaviors:

- They believe that they belong to school both academically and socially, the school is part of them and they see it as a pathway for future goals contributing for the family and the community;

- They are involved in learning, agreeing to get out of their "comfort zone" and learn more viewing the effort positively and postpone their current desires on behalf of school work;

- They see failure as a learning opportunity or problem to be solved, not as a humiliation, lack of their ability or not belonging to the group;

- They remain engaged in long-term learning and deploy new strategies for effective advancement.

Longitudinal intelligence research she has done shows that students' mindset predicts their academic performance in real terms. Namely, students with growth mindset show continuous improvement, and those with fixed mindset show no improvement even though their entrance tests at the institution show the same number of achievement points.

In 2007, Carol Dweck published a study article with 373 middle school students. She asked every child a simple question: "Is intelligence something very basic that really can't really change?" She sorted their respective answers into two fascinating groups. The kids from the "fixed mindset" group who answered yes were really good at learning and solid in knowledge. The other malleable group responded with a no, advocating that the intelligence can actually change. After a period of monitoring the respondents, Dr. Dweck discovered that the children in the first group were more concerned about looking smart than about the learning itself. When faced with setbacks, they perceive it as a crucial and a intrinsic failure, so they stop trying to learn. They had a negative attitude toward investing effort as a sign of low achieving, holding an attitude that a talented and intelligent person does not need to work hard in order to succeed. On the other hand, those with the attitude that intelligence can improve over time, were more interested in the learning for learning's sake. They were more willing to take risks even though they made mistakes. They worked hard because they thought they could become better. When faced with failure, they strategically regrouped and then tried again. They saw mistakes as opportunities to improve, learn and grow. Dr. Dweck calls this attitude "growth mindset". There are three attributes to being in a growth mindset: investing effort into learning, using good strategies and proactive help-seeking. That is why teachers are required to focus on the learning process, not just the product or outcome or grades. She points the power of the "yet" on the way to learning against the tyranny of the "now" in achieving results. Along the way it is very important for teachers to pay attention to the psychological moment when children face difficulties and struggle to do something. The teachers should identify those key moments and verbalize it with an appropriate vocabulary during the 
pedagogical guidance help. The same "value vocabulary" should be used to designate an error as an interesting, starting point for learning, grit and effort as entertainment, and awareness of not knowing the facts as an opportunity to know more. Reasonable praise during a child's specific process of achieving something encourages motivation and confidence, focusing more on activities that lead to success, and less on the product. Such a concept implies values exemplified by the teacher and values acquired by the student such as diligence, persistence, perseverance and optimism (Dweck, 2015). The following statements are an example of such communication:

- You are good at drawing, I like the detail you put on the girl's face.

- You have really learned about the test, you've read it many times, highlighted it and tested yourself, really worth it!

- I like the way you try different math strategies until you have come to the right solution.

- I like that you took part in the science project. It will take a long time to research, draw and do, and you will learn a lot along the way.

- Wow, this is hard, this is fun.

- Here's a wonderful mistake, let's see what we can learn from it, mistakes are wonderful.

"The Growth mindset" allow children to gain more confidence and endurance as well. Changing their mindset or attitude when they are out of the comfort zone and face difficulty or effort to master something, leads to greater connections of neurons in the brain which makes them smarter and achieves higher results and grades.

Carol Dweck works to develop the mindset of young people always emphasizing the power of the word yet in helping children on the road to success. Not yet does not mean failure on the path of learning and escaping difficulty, but it means that the skills are developed with grit and effort. The education is not about now, but about yet, the education is focused on tomorrow, not on good grades. Otherwise future students and workers are created who are accustomed to and depend on constant reward. How to cross the bridge to yet? She says praise should be reasonable, because praising talent and intelligence makes students vulnerable. Dweck says: "Don't tell your kids they are smart. Three decades researches show that focusing on 'process' - not intelligence or ability - is the key to school and life success" (Dweck, 2015). The school should provide a "growth mindset" learning environment that will enable equal access to education for all. This theory has changed the meaning of the word difficulty and effort in learning, from the meaning of the learner's inability to learn to possibility to become smarter and more intelligent, where "difficulty" means "not yet". However, the teacher may be stuck in his or her own fixed mindset, i.e., see some students as a problem children, not as a puzzle, and deprive those children who achieve results of being able to move forward and to work even harder. We believe that additional forms of training the teachers as a result of insufficient pedagogical competences acquired in initial education and teaching practice will take place to realize the value-based educational goals successfully.

\subsubsection{Strategies for Development of Growth Mindset}

Dweck's discovery of "fixed \& growth mindsets" changes our understanding of learning and the relationship between mindsets and achievements. Research on the plasticity of the brain suggests that the connection between neurons can change with experience. With action and practice, neuroscience creates new connections, reinforces existing ones and builds insulation that accelerates impulse transmission. These neuro-scientific discoveries have shown us that we can increase our neurons and cell growth through the actions we take, such as using good strategies, asking questions, practicing and following good eating and sleeping habits.

Therefore, the mental image of students is in the hands of teachers, mentors, parents, and educators who need to take care of its cultivation and growth. The strategies, or the frequently quoted principles for its implementation, are broadly explained, only briefly listed and outlined here:

- Lectures on mindset show the pupils that focused work can bring success;

- Safe place is needed for the pupils to take risks to learn;

- Teachers set micro goals as possibilities of levels of success of the kids;

- Reasonable praise is with focus on process not product work;

- The word "YET" is present during the learning process of effort;

- Mistakes are interesting to approach the solution to the problem; 
- Setting high expectations and support;

- Talk about your mindset (students learn from our examples and experiences); for help;

- Students have the opportunity to ask

- Success takes time and effort which does not incapability;

- Development of values of grit and endurance;

- New challenges to learn are not in the comfort zone;

- Use of records for assigned goals which are specific, achievable, measurable;

- Keeping the files of development;

- Allowing children to make mistakes and restart the work to find a solution.

\subsection{The Flow - Mihaly Csikszentmihalyi}

Mihai Csikszentmihalyi is a Hungarian psychologist known for the psychological concept of "Flow", which signifies a state in which people are so involved in an activity that nothing else seems to matter; the experience is so enjoyable that people will continue to do it even at great cost, for the sheer sake of doing it (Csikszentmihalyi, 1990). He builds this theory on the basis of positive psychology as well, which is of interest to us in terms of the favorable status of students in acquiring and learning values and skills for building personality. He was inspired by the happiness of some people that survived the war and has been exploring the puzzle of "what makes life worth living".

Although according to many studies the scarcity of material resources contributes to a state of misfortune, he notes that the increase in material goods does not lead to happiness in humans. He has been exploring the term happiness for 40 years with a focus on creative people as artists, scientists to find out what has led them to devote their entire lives to activities that made their lives significant and virtuous and worth living. One of the statements of his interviewees is a feeling of ecstasy, an intense feeling in which one does not feel the existence and consciousness. It is not a state of everyday life but a kind of alternative reality, the one possessed by successful ancient civilizations at the peak of their development in the construction and creation of various temples and buildings where they experienced the state of "flow". During the creativity action, a spontaneous process takes the stage that refers to someone who is trained and had developed knowledge and techniques in the appropriate field and feels this sense of creativity without an effort. "For the top poet it is an open door to heaven, for the famous composer it is a selfpropelled movement of the hand writing music notes, for the famous fashion designer it is a passion fulfilled when it works best in a 'flow' state, for the athlete's automatic movement, for the poor founder for Sonny it was the idea of a technological innovation's fortune, a process Einstein describes when he creates the theory of relativity." (ibid)

All of these professions can be chosen by our students who can be successful and happy in life, but the "flow" can also be realized at work, that is, the love for the teaching profession or any other to make teachers and people happy regardless of material status.

Central to his theory is creativity as the source of meaning in our lives. "When we are involved, deeply engaged in creativity, we feel we live more fully and fulfillingly than the rest of our life." (ibid, 4) He calls the creative moment "flow", a moment when a person is fully surrendered and engaged in the activity for the sake of it. The ego is gone, time flies, every moment, movement and thought follow one another, the whole being is left to activity, and the skills that the individual possesses are used to the fullest.

\subsubsection{Diagram of "FLOW"}

The FLOW diagram(Figure 3 ) represents this state of creative moment with other states close to it and the distant and opposing ones that reflect a given moment of an activity. Mihaly Csikszentmihalyi says that "The best moments usually occur if a person's body or mind is stretched to its limits in a voluntary effort to accomplish something difficult and worthwhile" (Csíkszentmihályi, 2012).

Measuring is precise, the amount of challenge being experienced at a given point is measured several times a day and the degree of skill adopted. For each person, a personal average is calculated as the centre of the diagram. Knowing this given point, one can predict exactly the state of the "flow" when the challenge is greater than average and skills higher than average. 


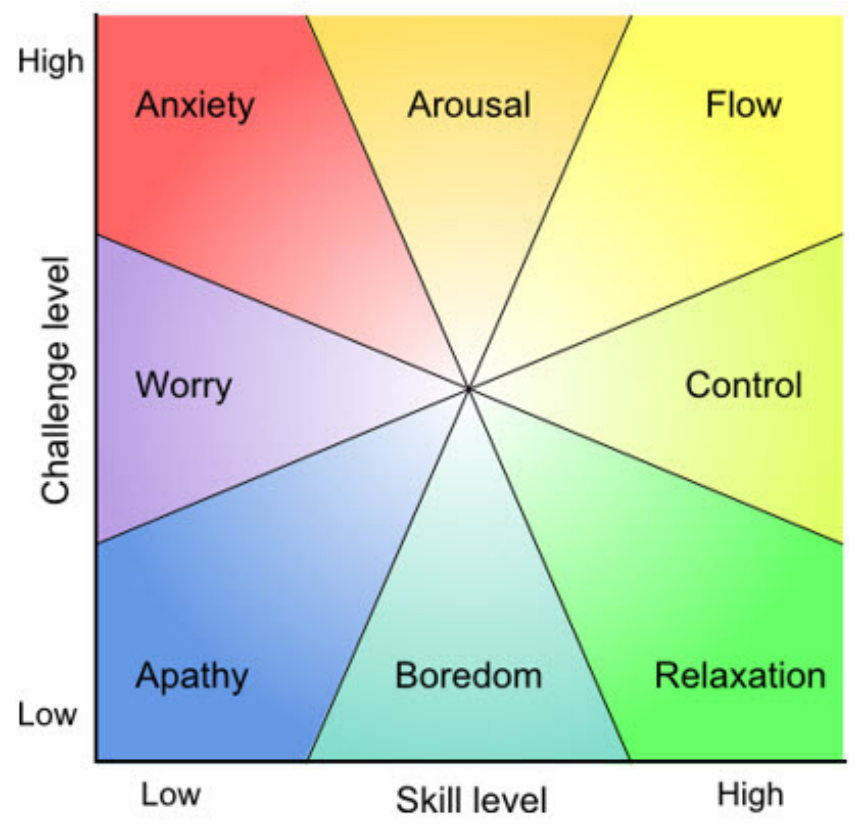

Figure 3. Csikszentmihalyi 's FLOW diagram

The Arousal is a state where there is too much challenge and the skills are not as great as needed but one can easily get to the state of flow with the development of the skill, this is the moment one learns the most because here the person comes out of the comfort zone.

The Control state is also a good place to be at, but there is not much excitement, a condition that is no longer challenging. If the person wants to get into a flow state, the challenge needs to be increased. These two states are complementary and can be easily switched to a flow state.

Other combinations of challenge and skills are less desirable. Relaxation is fine, Boredom starts to become repulsive and Apathy is very negative as there is no feeling that something is being done, the person is not using the skills, as no challenge exists. As the model participant in this experience, he points out to one watching television or using a mobile phone. What we need to do is try to put most of the time in a flow state. And it's a kind of challenge that many people are trying to understand but can't reach without additional help. When it comes to students, that responsibility lies within the teacher.

In the paper these three models in valuebased education teaching are exemplified, there exist other models and theories in pedagogical theory but for some of them there is a dilemma regarding the practical implications and teachers' competences to teach in this field.

\section{CONCLUSION}

These value-based models provide the school with opportunities to face the school challenges of the $21^{\text {st }}$ century and fulfil its function more autonomously in the education process. Values are complemented in the formation of the young man's character and thus all tasks of the education (material, functional and educational) are not treated in isolation but performed simultaneously. The results of these models' research show that the quality school is also possible for students with low family income or students of different cultural and national backgrounds with different GDPs that in the past have often been referred to as reasons for low academic achievement, which is similar to Glasser's description (1994) of what a "quality school" is.

The PERMA model teaches us how to make a fulfilling and happy life with a positive vision of each activity in learning and working. Children being happy in the activities while performing the tasks learn better and become more engaged in the learning activities. In doing so, the teacher needs to know the students well enough to offer them activities that will animate their curiosity and interest in a given activity. This way the goals are higher and the challenge greater in activities that are enjoyable.

The Model of Fixed and Growth Mindset of Carol Dweck focuses on improving the students' mindset and developing their positive 
thoughts and abilities through dedication and hard work. The power of positive thinking gives children, teachers, mentors and parents power to change their mindset, become selfconfident and improve learning outcomes and academic performance. This theory is especially applicable to students. There are many benefits to cultivating a "growth mindset" in children of all ages and it is never too late to start applying it. Teachers have a wonderful opportunity to influence the children they interact with on a daily basis, and by applying some techniques and strategies and special value vocabulary they can encourage them to develop their way of thinking and learning capacity.

The last model presented here is Mihaly Csikszentmihalyi's model of FLOW or creative experience and refers to high intrinsic motivation where self-consciousness fades, the personality completely surrenders to the present moment activity, and time means nothing, Csíkszentmihályi, 2012 just as skilled musicians plays without thinking and the surfer catches the wave. Mihaly identifies individuals who may experience a "flow" as being autotelic that is, individuals who are self-driving and intrinsically motivated to find the value in themselves, and what they do as an activity is the goal for itself. Almost any of us can improve our ability to experience this creative moment, but there are obstacles to do so. Most often they are in the person within who, if they are students, need the help of a teacher or a parent. He notes that individuals with a low concentration such as children with concentration disorders have difficulty in deepening into the activity and do not feel comfortable performing it (Csikszentmihalyi, 1990). Hence, we suggest that the teacher first has the task to develop the concentration of such children by helping techniques before introducing them to the activities during the lesson time due to the fact that they will not be successfully realized and achieved. This group includes also self-controlled and egocentric individuals and students who are preoccupied with themselves. The same would apply to children who are preoccupied with problems, worries and fears that impede their learning so that they lose opportunities for character development and value acquisition. They are excluded from activities that relate to pleasure and enjoyment and they cannot feel the "flow" moment. However, he points out that "the main inhibitors are social conditions and they are more difficult to overcome such as slavery, exploitation, the destruction of the cultural values that make people's life full of pain and thus lose the pleasure and the need to survive and reproduce." (ibid, 84-85)

The lack of social and ethical standards and social alienation make the experience of "flow" impossible to achieve, hence there is a greater reason to teach values in the school curriculum such as peace, non-discrimination, freedom, love, social intelligence and spirituality. Finally, Mihaly suggests that we can experience this sense of "flow" not only on our own, but also in relationship and communication with others around us, and we would add during the lessons, during an excursion, in a gym, doing experiments or reading literature works in a class. In fact, this is done by sharing the existence of many valuable artefacts and cultural heritage of various origins from the past as well as by transferring scientific knowledge for centuries up to the present moment.

\section{ACKNOWLEDGEMENTS}

I would like to express my gratitude to the university professor Phd Aneta Barakoska who supported my work and encouraged me to get results of better quality in the theoretical and field research of my doctoral thesis.

\section{Conflict of interests}

Author declares no conflict of interest

\section{REFERENCES}

Csikszentmihalyi, M. (1990). Flow. The Psychology of Optimal Experience. New York (HarperPerennial) 1990.

Csíkszentmihályi, Mihály: 19 Wikipedia Articles. (2012). Retrieved April 10, from http://www. markfoster.net/struc/Mihaly_Csikszentmihalyiwiki.pdf

Dweck, C. (2015). Carol Dweck revisits the growth mindset. Education Week, 35(5), 20-24. https:// portal.cornerstonesd.ca/group/yyd5jtk/Documents/Carol\%20Dweck\%20Growth\%20Mindsets.pdf

Dweck, C. S., Walton, G. M., \& Cohen, G. L. (2014). Academic Tenacity: Mindsets and Skills that Promote Long-Term Learning. Bill \& Melinda Gates Foundation. https://files.eric.ed.gov/fulltext/ED576649.pdf

Dweck, C. S. (2007). The secret to raising smart kids. Scientific American Mind, 18(6), 3643. https://mindfulbydesign.com/wp-content/ uploads/2015/05/4.-The-Secret-To-RaisingSmart-Kids.pdf

Glasser, W. (1994). Kvalitetna skola. [Quality School]. Educa Zagreb.

Levin, D. (2019, April). Character Growth Card. [Video file]. Retreived from https://www.coursera.org/ 
lecture/teaching-character/character-growthcard-Au73j

MerriamWebster dictionary. Retrieved December 10 2019 from https://www.merriam-webster.com/ dictionary/mindset

Mijatović, A., Vrgoč, H., Peko, A., Mrkonjić, A., \& Ledić, J. (Eds.). (1999). Osnove suvremene pedagogije. Hrvatski pedagoško-književni zbor.

Oxford Dictionary (2019). https://www.oxfordlearnersdictionaries.com/definition/english/mindset

Park, N., Peterson, C., \& Seligman, M. E. (2004). Strengths of character and well-being. Journal of social and Clinical Psychology, 23(5), 603-619. https://doi.org/10.1521/jscp.23.5.603.50748

Peterson, C., \& Seligman, M. E. (2004). Character strengths and virtues: A handbook and classification (Vol. 1). Oxford University Press. https://s3.amazonaws.com/academia.edu. documents/60644288/character-strengths-andvirtues20190919-80486-1xydkjl.pdf?responsecontent $-\mathrm{d}$ isposition $=$ inline $\% 3 \mathrm{~B} \% 20$ filename\%3DCharacter Strengths and Virtues A Handbo.p. $d f \& X-A m z-$ Algorithm $=\overline{A W} \overline{\mathrm{S}} 4-\mathrm{HMAC}-\mathrm{SHA} 256 \& \mathrm{X}$ A m z - Credential=A K I A I W O W Y Y GZ 2 Y 53 UL 3 A \% 2 F $20200127 \% 2$ F us-east- $1 \% 2 \mathrm{Fs} 3 \% 2 \mathrm{Faws} 4$ request $\& \mathrm{X}$ $\mathrm{Amz}-\mathrm{D}$ ate $=20200127 \mathrm{~T} 1 \overline{3} 1302 \mathrm{Z} \& \mathrm{X}-$ A m z - E x p i r e s = $3600 \%$ \& Amz-SignedHeaders $=$ host \&X-Amz-Signatur $\mathrm{e}=\mathrm{f} 904766 \mathrm{~d} 7 \mathrm{aaf} 3 \mathrm{dfe} 0 \mathrm{~b} 7 \mathrm{c} 9 \mathrm{~d} 5585 \mathrm{~d} 5462 \mathrm{f} 80 \mathrm{f}-$ f45ec9f78e5a8f070d2becc3bbe6a

Rokeach, M. (1973). The nature of human values. Free press. https://psycnet.apa.org/record/2011-15663-000

Seligman, M. (2011, April) Authentic Hapiness. Retrieved from https://www.authentichappiness. sas.upenn.edu/newsletters/flourishnewsletters/ newtheory

Seligman, M. (2018). PERMA and the building blocks of well-being. The Journal of Positive Psychology, 13(4), 333-335. https://doi.org/10.1080/17 439760.2018 .1437466

Seligman, M. (2019). Teaching Character and Creating Positive Classrooms: PERMA - Interview with Dr. Martin Seligman. Retrieved February 10, 2019 from https://www.coursera.org/learn/ teaching-character/lecture/j0HF4/perma-interview-with-dr-martin-seligman

Schwartz, S. H. (1994). Are there universal aspects in the structure and contents of human values? Journal of social issues, 50(4), 19-45. https:// doi.org/10.1111/j.1540-4560.1994.tb01196.x

Schwartz, S. H. (2012). An overview of the Schwartz theory of basic values. Online readings in Psychology and Culture, 2(1), 2307-0919. https:// doi.org/10.9707/2307-0919.1116 